\title{
Analysis of Extreme Precipitation under the New Low Radiative Forcing Scenario in the Inland River Basin of Northwest China
}

\author{
Lianqing Xue ( $\sim$ lqxue@hhu.edu.cn) \\ Hohai University \\ Mingjie Yang \\ Hohai University \\ Yuanhong Liu \\ Hohai University \\ Yixia Chi \\ Jiangsu University of Science and Technology \\ Yunbiao Wu \\ Hohai University \\ Jing Wang \\ Hohai University
}

\section{Research Article}

Keywords: GCMs, extreme precipitation index, IRB, extreme precipitation

Posted Date: January 25th, 2022

DOI: https://doi.org/10.21203/rs.3.rs-1222944/v1

License: (1) This work is licensed under a Creative Commons Attribution 4.0 International License.

Read Full License 


\section{Abstract}

With global warming, extreme weather events in various regions have become more abnormal. To study the variation characteristics of extreme precipitation in the inland river basin (IRB) of Northwest China, this paper selected four global climate models (GCMs) under a low radiative forcing scenario to analyze eight-core extreme precipitation indices in the basin. According to the changes of each index in the near future (NF) and the far future (FF), the changes of extreme precipitation have been determined under a low radiative forcing scenario in the basin. Our study shows that all four models can capture seasonality and all have uncertainty. The PRCPTOT showed a trend of decreasing from the center to the southeast and northwest. The SDII showed opposite trends in mountainous and central desert regions. The number of CDD will decrease, while the CWD will change significantly. The P1025 and PG25 will increase by more than $50 \%$. The Rx1day and Rx5day are mainly distributed in some areas such as the desert and Gobi. Although we have predicted the future trend of extreme precipitation in the IRB, the precise prediction of extreme precipitation remains to be further studied.

\section{Introduction}

Since the Industrial Revolution, the massive emission of carbon dioxide and other greenhouse gases has gradually warmed the global climate. The frequency of global extreme precipitation events has increased significantly in the context of global warming(Berg et al., 2013; Donat et al., 2016; Easterling et al., 2016). Compared with the long-term continuous increase in temperature, changes in extreme precipitation events are more likely to cause serious casualties and property losses (Zhang and Zhou, 2020). Therefore, accurate simulation and prediction of extreme precipitation are particularly important(Bai et al., 2007; Chen et al., 2012; Prein et al., 2016). GCMs are the most important tool available for simulating climate, for investigating the response of climate to various forcing, and for making predictions and projections of future climate (IPCC, 2013). The model results of the Coupled Model Intercomparison Project (CMIP) directly support the writing of the Intergovernmental Panel on Climate Change (IPCC) assessment report (Zhou et al., 2019). The simulation data of the Coupled Model Intercomparison Phase 6 (CMIP6) has been submitted so far. Therefore, the use of CMIP6 data for extreme precipitation analysis has become a new research focus.

The number of rainfall days has decreased in most regions of China since the 1960s (Liu et al., 2005), but the total annual rainfall has increased significantly (Zhu et al., 2011), and the corresponding extreme precipitation events have become more frequent (Wang et al., 2012). Some scholars have used highresolution regional models to estimate the future precipitation and extreme precipitation in China (Gao et al., 2011). The results show that extreme precipitation events have generally increased throughout China in the 21 st century. In addition, there are also significant differences between different regions. Studies have shown that extreme precipitation events in North China and the central part of Northeast China show a slow increase trend(Qian et al., 2007; Wang and Li, 2005), while the southeast coast, the middle and lower reaches of the Yangtze River and the northwest inland areas show a significant increase trend(Gemmer et al., 2008; Li et al., 2018). The northwestern region is replenished by precipitation and 
mountain snowmelt water. It is an arid and semi-arid region, which is more sensitive to precipitation fluctuations (Zhu et al., 2018).

Guo et al. (2014) analyzed the temporal and spatial distribution of summer extreme precipitation frequency by using the data of summer daily precipitation at 153 meteorological stations in Northwest China from 1963 to 2012. Rao et al. (2019) evaluated 32 climate models from CMIP5 compared with 3 extreme precipitation indices over Northern China during the historical period (1986-2005) and selected the best performance model ensemble for projecting climate change of extreme rainfall events under RCP4.5 and RCP8.5 scenarios. Srivastava et al. (2020) evaluated the simulated historical for CMIP6 models by using precipitation indices defined by the Expert Team on Climate Change Detection and Indices in the United States. A comparative assessment of model capabilities in simulating precipitation extremes across China was implemented by using 30 models from the CMIP5 and using 36 CMIP6 models (Xu et al., 2021). Chen et al. (2021) evaluated the performance of the CMIP6 models in simulating the seasonal evolution and extreme precipitation indices in the western North Pacific and East Asia region, and compare the results with those from CMIP5. Most people's research focuses on RCP2.6, RCP4.5, and RCP8.5. The recently launched new generation CMIP6 framework proposes a new low radiative forcing under the Shared Socioeconomic Pathways (SSPs1-1.9), and this kind of low forcing radiation scenario has not appeared in CMIP5 in the past. The climate models under SSPs1-1.9 have been developed to limit the temperature increase to $1.5^{\circ} \mathrm{C}$ to achieve the sustainability goals in the Paris Agreement (Eyring et al., 2016; Stouffer et al., 2017). However, there is still a lack of relevant research using this low radiative forcing scenario to analyze extreme precipitation in Northwest China.

In this study, we use four CMIP6 GCMs under the Shared Socioeconomic Pathways 1-1.9. The aim of the paper is twofold. Firstly, to correct the four CMIP6 GCMs based on the CN05.1 grid observation data set obtained by more than 2400 national-level stations of the National Meteorological Information Center in China. Secondly, to explore the changes of extreme precipitation indices of the NF (2021-2050) and the FF (2071-2100) in the IRB of Northwest China and their impact on precipitation in the basin. The study results could provide useful information for the formulation of sustainable water resource utilization policies and the harmonious and stable development of society in Northwest China.

\section{Materials And Methods \\ 2.1. Study area}

Based on the principles of the Chinese Academy of Sciences Resource and Environment Data Center for the division of national water resources, this paper divides the country into nine major river basins according to river basins (Fig. 1) (Xu et al., 2019). IRB is located in northwestern China, between $29^{\circ} \mathrm{N} \sim 49^{\circ} \mathrm{N}$ and $73^{\circ} \mathrm{E} \sim 120^{\circ} \mathrm{E}$, with a total drainage area of 3.35 million $\mathrm{km}^{2}$. The IRB of Northwest China mainly includes Gangdese Mountains, Bayan Har Mountains, Kunlun Mountains, Tianshan Mountains, Altai Mountains, Qilian Mountains, Helan Mountains, Yinshan Mountains, Daxinganling Mountains, 
Taklimakan Desert, and Gurbantungut Desert. It is far from the ocean and the climate is arid. The average annual precipitation for many years is only 172mm (Guohua et al., 2016).

\subsection{Data}

Five models of CANESM5 (CE), GFDL-ESM4 (GE), MRI-ESM2 (ME), MIROC6 (MI), and IPSL-CM6A-LR (IL) have provided the simulation results of SSPs1-1.9. The atmospheric resolution of CE is $500 \mathrm{~km}$, while the other four models are $100 \mathrm{~km}$ and $250 \mathrm{~km}$ (Gupta et al., 2020). Therefore, four models have been selected for this study, namely GE, ME, MI, and IL. Basic information on the models is given in Table 1. Further details can be obtained online at https://www.wcrp-climate.org/wgcm-cmip.

Table 1

Basic information about the 4 GCMs in this study

\begin{tabular}{|llllll|}
\hline Abbreviation & Model ID & $\begin{array}{l}\text { Country or } \\
\text { Union }\end{array}$ & $\begin{array}{l}\text { Atmospheric } \\
\text { resolution }\end{array}$ & $\begin{array}{l}\text { Integration } \\
\text { period }\end{array}$ & Type and size \\
\hline GE & $\begin{array}{l}\text { GFDL- } \\
\text { ESM4 }\end{array}$ & USA & $100 \mathrm{~km}$ & $1950-2100$ & $\begin{array}{l}\text { Daily } \\
\text { precipitation }\end{array}$ \\
\hline ME & MRI-ESM2 & Japan & $100 \mathrm{~km}$ & $1950-2100$ & $\begin{array}{l}\text { Daily } \\
\text { precipitation }\end{array}$ \\
\hline MI & MIROC6 & Japan & $250 \mathrm{~km}$ & $1960-2100$ & $\begin{array}{l}\text { Daily } \\
\text { precipitation }\end{array}$ \\
\hline IL & $\begin{array}{llll}\text { IPSL- } \\
\text { CM6A-LR }\end{array}$ & France & $250 \mathrm{~km}$ & $1850-2100$ & $\begin{array}{l}\text { Daily } \\
\text { precipitation }\end{array}$ \\
\hline
\end{tabular}

Precipitation data applied for evaluation is obtained from a daily $0.25^{\circ} \times 0.25^{\circ}$ meteorological dataset during 1961-2018 (CN05.1). The dataset is obtained by superimposing the climate field and the anomaly field after interpolating respectively from the observation data of more than 2400 stations in China by using the anomaly approximation method (Wu and Gao, 2013).

To ensure the accuracy and consistency of the data, we adopt $1^{\circ} \times 1^{\circ}$ spatial resolution and select the precipitation data from 1961 to 2014 as the baseline period, 2021-2050 as the NF, and 2071-2100 as the FF.

\subsection{Bias correction}

In this study, we evaluate the four models by the percentage of deviation and the root mean square error (RMSE). Climate model output data suffer from various types of inherent biases. Therefore, it becomes essential to correct these biases before impact assessment analysis (Cannon, 2017; Maraun and Douglas, 2013). We correct the bias of the four models' output by using Equidistant Cumulative Distribution Functions (EDCDF). This method combines and adjusts the cumulative distribution functions (CDF) of the model during the forecast period based on the difference between the model and the 
observed cumulative distribution functions in the baseline period (Li et al., 2010; Ren et al., 2017; Wang et al., 2017). The EDCDF is defined as:

$$
X_{M F-C}=X_{M F}+F_{O H}^{-1}\left[F_{M F}\left(X_{M F}\right)\right]-F_{M H}^{-1}\left[F_{M F}\left(X_{M F}\right)\right]
$$

where $X_{M F}$ and $X_{M F-C}$ are respectively the future simulation value and deviation correction value of the model, $F_{M F}$ is the CDF in the future, $F_{O H}^{-1}$ is the inverse function of the CDF of historical observation data, while $F_{M H}^{-1}$ is the inverse function of the CDF of historical data in the model.

\subsection{Precipitation extreme indices}

To explore the changing nature of climate change in the IRB of Northwest China simulated in CMIP6 under SSP1-1.9, we used eight-core extreme precipitation indices. They are PRCPTOT, SDII, CDD, CWD, P1025, PG25, Rx1day, and Rx5day. The SDII is the PRCPTOT divided by the number of days with precipitation greater than or equal to $1 \mathrm{~mm}$. Table 2 shows the characteristics of the extreme precipitation indices used.

\section{Results}

\subsection{Seasonality variability in CMIP6 historical data}

The four seasons are distinct in the IRB of northwest China, the climate is dry, and the distribution of precipitation is extremely uneven during the year. The maximum annual average precipitation in winter and autumn in various regions is around $200 \mathrm{~mm}$, while the value in spring and summer is around $450 \mathrm{~mm}$. The average summer rainfall in the Gangdise Mountains in the southeast exceeds $450 \mathrm{~mm}$, while the average winter rainfall in the desert area does not exceed $5 \mathrm{~mm}$. Fig. 2 shows the comparison of the seasonal variation between the actual precipitation in CN05.1 and the selected four CMIP6 climate model datasets.in the IRB. These data were divided into four seasons, namely winter (December-February), spring (March-May), summer (June-August), and autumn (September- November).

Figure 2 displays that the maximum annual average precipitation is $240 \mathrm{~mm}$ in winter (Fig. 2a-2e), $500 \mathrm{~mm}$ in spring (Fig. 2f-2j), 550mm in summer (Fig. 2k-2o), and 220mm in autumn (Fig. 2p-2t). The IRB has complex landform types, including snow-capped mountains, oases, and deserts, which makes precipitation in seasons show huge spatial differences. Comparing the basic data of the selected CMIP6 climate models, an almost similar spatial distribution of precipitation was observed in all climate models. In spring, the simulated precipitation of each model shows the decreasing trend from northwest and southwest to northeast and southeast, while the precipitation shows a decreasing trend from southwest to northeast in summer.

Comparing the precipitation distribution maps of each season horizontally, the precipitation data of the IL model is the closest to the historical observations. The IL model can well represent the extremely high 
value of precipitation in the precipitation data of spring and summer, while the GE model can capture that in winter and autumn. The MI model overestimates the precipitation in the IRB, especially in the southwestern region of each season. The ME model's estimation of precipitation in this area is not stable enough. The winter is generally low, and the other three seasons are low in some places and high in some places.

\subsection{Model evaluation and bias correction}

Figure 3 shows the percentage biases of the selected CMIP6 GCMs and the change results of the RMSE concerning the observed precipitation of each grid during the period 1985-2014. In Figs. (3a-3d), the negative and positive values respectively represent the underestimation and overestimation of the precipitation data based on the four models of CMIP6 GCMs compared with the observed data. In the GE, $\mathrm{ME}$, and $\mathrm{MI}$ plots, the deviation values of most regions are between $-50 \%$ and $100 \%$, while the deviation values of most regions in the IL plot are between $-100 \%$ and $75 \%$. Figs. $3 a-3 d$ shows that the deviations in the northern and southern regions are generally between $-50 \%$ and $50 \%$, and the areas with large deviations are mainly concentrated in the southwest and central desert regions. The comparison of the deviations of these four plots shows that the deviation of the GE plot is relatively small, while the deviation of the MI graph is relatively large. In Figs. (3e-3h), the RMSE of almost all regions remains at 05 , and only the RMSE of individual regions in the northeast and southwest exceeds 5 . Comparing the RMSEs of the four plots, the RMSE of the IL plot is overall smaller, while the MI graph is overall larger. It reflects that the IL model-based precipitation data and the observed data have a small degree of dispersion, which tends to be stable.

Figure 4 reflects the deviation percentages of the four models after correction with the EDCDF compared to the observed data. Figs. $4 \mathrm{a}-4 \mathrm{c}$ shows that the deviation percentages in most regions are between $-1 \%$ and $1 \%$, and the deviation percentages in individual central regions such as the Taklimakan Desert are between $-4 \%$ and $4 \%$. The overall deviation correction effect of the IL plot is better, except that the deviation value of the individual areas in the middle is kept at about $5 \%$.

\subsection{Variability in precipitation extremes during historical events}

Figure 5 shows the average extreme precipitation indices calculated using the observed precipitation datasets during the period 1961-2014. Figs. 5a-5i shows the average values of the observed precipitation, PRCPTOT, SDII, CDD, CWD, P1025, PG25, Rx1day, and Rx5day calculated from 1961 to 2014, respectively. It can be seen that the southeast region and the vicinity of the Tianshan Mountains have the highest precipitation from Fig. 5a, while the central desert region has the least precipitation. The PRCPTOT in Fig. $5 \mathrm{~b}$ and annual average precipitation in Fig. $5 \mathrm{a}$ shows similar distributions. From Fig. 5b and Fig. 5c, it can be seen that the PRCPTOT and the SDII have a strong correlation, especially in the southeast and northwest regions, while the correlation is poor in the central desert area and the Kunlun Mountain area. 
The maximum observed CDD appears in the Taklimakan Desert area, and the minimum appears in the northwestern region (Fig. 5d). The CWD value of the IRB in the northwest is generally small, and the CWD value is large only in the eastern part of Qilian, near the Tianshan Mountains and the Qinghai-Tibet Plateau in the south (Fig. 5 e). The number of moderate rain days with daily precipitation of $10-25 \mathrm{~mm}$ only occurs in the Tianshan Mountains, the southern part of Gangdise Mountains, the eastern part of Qilian Mountains, and the Daxingan Mountains in the northeast (Fig. 5f). Heavy rain with a daily rainfall of more than $25 \mathrm{~mm}$ only occurs in the Daxinganling Mountains in the northeast, and the annual average value is 1.5 days (Fig. $5 \mathrm{~g}$ ). The distribution of Rx 1 day and Rx5day in the IRB is highly consistent, showing a trend of decreasing from the southeast and northwest to the middle (Fig. 5h-5i). The maximum value of Rx1day is about $35 \mathrm{~mm}$, and the maximum value of Rx5day is about $60 \mathrm{~mm}$.

\subsection{Analysis of extreme precipitation in the future}

Figures $6 a-6 \mathrm{~d}$ and Figs. $6 \mathrm{e}-6 \mathrm{~h}$ respectively shows the change rate of the PRCPTOT of the four selected GCMs in the NF (2021-2050) and the FF (2071-2100) compared to the observed data, and Figs. 6i-6I and Figs. $6 \mathrm{~m}-6 \mathrm{p}$ respectively shows the percentage change of SDII in the two periods. The PRCPTOT change rate of different GCMs in different periods showed a trend of decreasing from the center to the southeast and northwest. The spatial distribution of the PRCPTOT change rate in the NF and the FF of the same GCM is relatively similar. The rate of change of the PRCPTOT in the NF and the FF has not changed much in the Altai Mountains, Tianshan Mountains, Gangdise Mountains, Qilian Mountains, Helan Mountains, and Daxingan Mountains. However, the change rate of the PRCPTOT has changed greatly in the Gurbantunggut Desert, the Taklimakan Desert, and the Hami-Yinshan region. The PRCPTOT change rates of GE and ME in the FF are greater than those in the NF in the central Taklimakan Desert, the Gurbantungut Desert, and the Hami-Yinshan region (Figs. 6a-6b and 6e-6f). The PRCPTOT index of the Taklimakan Desert in the FF is 6 times that of the observed data, while that of the NF is only 2 times. In the $\mathrm{MI}$ and IL models (Figs. 6c-6d and 6g-6h), both times (i.e., NF and FF) have shown a similar spatial distribution of the PRCPTOT, that is, the annual precipitation has increased significantly in the desert area.

In the GE and ME models (Fig. $6 \mathrm{i}$ and $6 \mathrm{j}$ ), the percentage change of SDII in the NF shows that the surrounding areas such as Tianshan, Kunlun, Qilian, and Daxinganling Mountains are around $-10 \%$, while the central desert area is around $+10 \%$, and the Gangdise Mountain is around $+30 \%$. The percentage change of the SDII in the FF of the Tianshan, Kunlun, Qilian, and Taklimakan Desert areas will decrease compared to the NF, while the Gangdise Mountains in the southeast will increase (Fig. $6 \mathrm{~m}$ and $6 \mathrm{n}$ ). In the $\mathrm{MI}$ and IL models (Fig. $6 \mathrm{k}$ and $6 \mathrm{I}$ ), the percentage change of the SDII in the NF is similar to the other two models, except that the values of some grids in desert areas are more negative. However, some grid values in the central desert area will decrease in the FF and will decrease in the south and east, especially in the Gangdise Mountains and Qilian Mountains (Fig. 60 and 6p).

Figures 7a-7d and Figs. 7i-7I respectively displays the percent of change CDD and CWD indices of the four selected GCMs compared to the observed value during the NF time (2021-2050), while Figs. 7e-7h and Figs. 7m-7p displays that of the FF (2071-2100). In the GE and ME models (Figs. 7a-7b and 7e-7j), it 
can be seen that some grids in the southeast and northeast regions show positive changes in different periods, such as Qilian Mountains, Gangdisi Mountains, and Daxinganling Mountains, while most of the grids in the desert, northwest and southwest regions, such as the Kunlun Mountains and the Altai Mountains show negative changes. In the MI and IL models (Figs. 7c-7d and 7g-7h), the distribution of the CDD change percentage in the NF is similar to the other two models, but there will be subtle changes in the FF, which are mainly reflected in the Tianshan Mountains and the Altai Mountains. The change rate of some grids in the Altai Mountains and Tianshan Mountains has increased by more than $80 \%$. In general, the CDD change percentage of most grids in different periods and different models corresponds to $-60 \%$ to $+20 \%$.

In the GE and ME models (Fig. 7i and $7 \mathrm{j}$ ), the CWD change percentage of most grids will exceed $40 \%$, and only some grids will show negative values in the NF, such as Tianshan, Kunlun Mountains, and Qilian Mountains. However, most of the grids in the FF are above 80\%, except for the Qinghai-Tibet Plateau from the Kunlun Mountains to Gangdis Mountains, Qilian Mountains, and Tianshan Mountains (Fig. 7m and 7n). In the MI and IL models (Fig. 7k and 7l), the distribution is quite different from the other two models in the NF, and most of the grids exceed $80 \%$. Only a small part of the grids are negative, mainly distributed in Tianshan, Kunlun, and Qilian Mountains. The distribution of the percentage change of the CWD is nearly half of the negative value in the FF, distributed in mountainous areas, such as the Altai Mountains, Tianshan Mountains, and the Kunlun Mountains, as well as desert areas (Fig. 7o and 7p). In general, the CWD change percentage of most grids in different periods and different models corresponds to $-10 \%$ to $+100 \%$.

Figures 8a-8d and Figs. 8i-8I respectively shows the percentage of change in P1025 and PG25 of the four selected GCMs in the NF, while Figs. 8e-8h and Figs. 8m-8p shows that of the FF. In the GE model (Fig. 8a), most of the grids in the entire watershed show positive values in P1025, especially in desert areas, while a few grids in Tianshan, the Kunlun Mountains, and Qilian Mountains show negative values. Compared with the NF (Fig. 8e), the spatial distribution of the percentage change has a strong consistency in the FF, but the positive value is not obvious in the desert area. In the ME model (Fig. 8b and 8f), both NF and FF show a spatial distribution similar to the GE model in P1025. However, the percentage changes of the grids in the central desert area and the Gangdise Mountains are slightly different from those of the GE model in the NF. In the MI and IL models (Figs. 8c-8d and 8g-8h), the percentage change of the P1025 of most grids in the NF and the FF corresponds to 0 to $10 \%$, some grids in desert areas exceed $20 \%$, and the grid values of Tianshan, Kunlun, and Gangdese mountains correspond to $-5 \%$.

In the GE and ME models (Figs. 8i-8j and 8m-8n), the percentage change of PG25 for most grids in the Tianshan, Kunlun, Qilian, and Daxinganling Mountains regions is negative in different periods, while most grids in the Taklimakan Desert, Hami-Yinshan, and Gangdise Mountains correspond to $+40 \%$. Comparing the grid changes of the two models in different periods, it is found that the positive grid in the FF shows a significant decreasing trend. In the MI and IL models (Figs. 8k-8I and 8o-8p), compared with the observed value, the percentage change of PG25 is concentrated in the Taklimakan Desert, the Gangdise Mountains of the Qinghai-Tibet Plateau, the Hami-Yinshan Mountains, and the Qilian Mountains. 
Figures 9a-9d and Figs. 9i-9l respectively shows the percentage of change in Rx1day and Rx5day of the four selected GCMs in the NF, while Figs. 9e-9h and Figs. 9m-9p shows that of the FF. For most of the IRB, the range of variation is from $-30 \%$ to $+100 \%$. In the GE and ME models (Figs. 9a-9b, 9e-9f, 9i-9j, and 9m$9 n)$, they display almost similar characteristics of Rx1day and Rx5day in different periods. The grids of each graph are positive, except for some grids in the Altai Mountains, Tianshan Mountains, Kunlun Mountains, Qilian Mountains, and Hami regions. However, the spatial distributions shown by MI and IL models are different from GE and ME (Figs. 9c-9d, 9g-9h, 9k-9l, and 9o-9p). And the percentage of changes in the grid reflected by them is generally low.

\section{Discussion And Conclusions}

In this study, we have used the eight extreme precipitation indices of four CMIP6 GCMs to analyze the extreme precipitation in the NF and the FF in the IRB when the global warming level is lower than $1.5^{\circ} \mathrm{C}$. The study found that the four models can capture the seasonality, especially the IL model, whose simulated data are closest to the observed data. Many previous studies (Kharin et al., 2013; Swain and Hayhoe, 2015; Thibeault and Seth, 2014) have shown that GCMs contain a significant amount of uncertainty, which has a serious impact on the assessment of future climate. Like the previous CMIP program, CMIP6 also shows similar uncertainties, which vary by region and altitude (Xue et al., 2017).

The CMIP6 GCMs behave differently in the simulation of annual precipitation in different regions, and it has a certain correlation with altitude. The precipitation in the Taklimakan Desert, the Gurbantungut Desert, and the Gobi area from Hami to Yinshan increased by 2-6 times, while the precipitation in the mountainous areas did not change much. At the end of July 2021, the Yuqi area located in the Taklimakan Desert was hit by floods, covering an area of more than 300 square kilometers, which confirmed the simulation results. In the future, some areas in the deserts, Gobi, and mountains will have more large flows and short-lasting precipitation, which will be more prone to flood disasters.

The number of accumulated dry days in the northwest IRB will decrease, which means that precipitation will become more frequent and last longer in most areas. The Tianshan Mountains, Taklimakan Desert, Kunlun Mountains, Gangdise Mountains, and Qilian Mountains will show the most obvious performance. This may be caused by changes in the subtropical highs in the Western Pacific and North America caused by global warming, while high mountain areas may be affected by altitude at the same time. The annual average number of consecutive precipitation days in the entire basin has changed significantly, especially in the southeast and north of the Kunlun Mountains, while some grids in the Gangdise Mountains of the Qinghai-Tibet Plateau show a significant decreasing trend.

The future number of moderate rain days will generally increase in the entire IRB, while the increase in heavy rain days will be mainly concentrated in the mountains, deserts, and Gobi areas. With the increase of people's awareness of environmental protection and the control of global warming, the number of heavy rain days in the FF will show a decreasing trend, especially in the desert and Gobi areas. In addition, moderate to heavy rains have increased by more than $50 \%$ in the desert, Gobi, and Gangdese 
mountains of the Qinghai-Tibet Plateau, which may make these areas more abundant in vegetation. Similarly, Rx1day and Rx5day reflect similar distributions to other indices. The areas with the largest growth are mainly distributed in the desert and Gobi areas, and some are distributed in the Gangdise Mountains and Yinshan-Daxinganling area.

Even when the global temperature rises by $1.5^{\circ} \mathrm{C}$, climate change still has a huge impact on precipitation in the northwestern IRB. Although we predict the future trend of extreme precipitation in the IRB, the precise prediction of extreme precipitation still needs further research. This is not only important for disaster prevention and control but also important for the formulation of sustainable water resources utilization policies in Northwest China and the harmonious and stable development of society.

\section{Declarations}

\section{Acknowledgements}

This study was supported by the National Scientific Foundation of China (NSFC) (No.51779074). It was acknowledged by Jiangsu water conservancy science and technology project (2019031) and the Key Projects of Natural Science Research in Colleges and Universities in Anhui Province (KJ2019A1279 \& KJ2020A0839).

\section{Competing Interests}

The authors declare that they have no conflict of interest.

\section{Author Contributions}

Mingjie Yang: Conceptualization; resources; writing-original draft; writing-review \& editing. Lianqing Xue: Conceptualization; writing review \& editing. Yuanhong Liu: Methodology; software; validation. Yixia Chi: Methodology. Yunbiao Wu: Formal analysis. Jing Wang: Software.

\section{References}

1. Bai, A., Zhai, P.M. and Liu, X.D. (2007) Climatology and trends of wet spells in China. THEOR APPL CLIMATOL, 88(3-4): 139-148. https://doi.org/10.1007/s00704-006-0235-7

2. Berg, P., Moseley, C. and Haerter, J.O. (2013) Strong increase in convective precipitation in response to higher temperatures. NAT GEOSCl, 6(3): 181-185. https://doi.org/10.1038/ngeo1731

3. Cannon, A.J. (2017) Multivariate quantile mapping bias correction: an N-dimensional probability density function transform for climate model simulations of multiple variables. CLIM DYNAM, 50(1): 1-19. https://doi.org/10.1007/s00382-017-3580-6 
4. Chen, C.A., Hsu, H.H. and Liang, H.C. (2021) Evaluation and comparison of CMIP6 and CMIP5 model performance in simulating the seasonal extreme precipitation in the Western North Pacific and East Asia. WEATHER CLIM EXTREME, 31: 100303. https://doi.org/10.1016/j. wace.2021.100303

5. Chen, H.P., Sun, J.Q., Chen, X.L. and Zhou, W. (2012) CGCM projections of heavy rainfall events in China. INT J CLIMATOL, 32(3): 441-450. https://doi.org/10.1002/joc.2278

6. Donat, M.G., Lowry, A.L., Alexander, L.V., O'Gorman, P.A. and Maher, N. (2016) More extreme precipitation in the world's dry and wet regions. NAT CLIM CHANGE, 6(5): 508-513. https://doi.org/10.1038/NCLIMATE3160

7. Easterling, D.R., Kunkel, K.E., Wehner, M.F. and Sun, L. (2016) Detection and attribution of climate extremes in the observed record. WEATHER CLIM EXTREME, 11(C): 17-27. https://doi.org/ 10.1016/j.wace.2016.01.001

8. Eyring, V., Bony, S., Meehl, G.A., Senior, C.A., Stevens, B., Stouffer, R.J., Taylor, K.E. (2016) Overview of the Coupled Model Intercomparison Project Phase 6 (CMIP6) experimental design and organization. GEOSCI MODEL DEV, 9(5): 1937-1958. https://doi.org/10.5194/gmd-9-1937-2016

9. Gao, X.J., Shi, Y. and Giorgi, F. (2011) A high resolution simulation of climate change over China. Sci China Earth Sci, 54(003): 462-472. https://doi.org/10.1007/s11430-010-4035-7

10. Gemmer, M., Tong, J., Su, B. and Kundzewicz, Z.W. (2008) Seasonal precipitation changes in the wet season and their influence on flood/drought hazards in the Yangtze River Basin, China. QUATERN INT, 186(1): 12-21. https://doi.org/10.1016/j.quaint.2007.10.001

11. Guo, P.W., Zhang, X.K., Shuyu, Z.Y., Wang, C.L. and Zhang, X. (2014) Decadal variability of extreme precipitation days over Northwest China from 1963 to 2012. J METEOROL RES-PRC, 28(6): 10991113. https://doi.org/10.1007/s13351-014-4022-6

12. Guohua, F., Heshuai, Q., Xin, W. and Lei, Z. (2016) Analysis of spatiotemporal evolution of extreme monthly precipitation in the nine major basins of China in 21 st century under climate change. JOURNAL OF NATURAL DISASTERS, v.25(02): 015-25. https://doi.org/10.13577/j. jnd.2016.0202

13. Gupta, V., Singh, V. and Jain, M.K. (2020) Assessment of precipitation extremes in India during the 21st century under SSP1-1.9 mitigation scenarios of CMIP6 GCMs. J HYDROL, 590: 1-16. https://doi.org/10.1016/j.jhydrol.2020.125422

14. IPCC (2013) Climate Change 2013凶The Physical Science Basis. Contribution of Working Group $\nabla$ to the Fifth Assessment Report of the Intergovernmental Panel on Climate Change. Cambridge $\mathbb{X}$ Cambridge University Press: 1535pp.

15. Kharin, V., Zwiers, F., Zhang, X. and Wehner, M. (2013) Changes in temperature and precipitation extremes in the CMIP5 ensemble. CLIMATIC CHANGE, 119(2): 345-357. https://doi. org/10.1007/s10584-013-0705-8

16. Li, H., Sheffield, J. and Wood, E.F. (2010) Bias correction of monthly precipitation and temperature fields from Intergovernmental Panel on Climate Change AR4 models using equidistant quantile matching. J GEOPHYS RES-ATMOS, 115(D10): 1-20. https://doi.org/10.1029/2009JD012882 
17. Li, W., Jiang, Z.H., Zhang, X.B., Li, L. and Sun, Y. (2018) Additional risk in extreme precipitation in China from 1.5 degrees $C$ to 2.0 degrees $C$ global warming levels. SCI BULL, 63(4): 228-234. https://doi.org/10.1016/j.scib.2017.12.021

18. Liu, B.H., Xu, M., Henderson, M. and Qi, Y. (2005) Observed trends of precipitation amount, frequency, and intensity in China, 1960-2000. J GEOPHYS RES-ATMOS, 110(D8): 1-10. https://doi.org/ 10.1029/2004JD004864

19. Maraun D. (2013) Bias Correction, Quantile Mapping, and Downscaling: Revisiting the Inflation Issue. J CLIMATE, 26(6): 2137-2143. https://doi.org/10.1175/JCLI-D-12-00821.1

20. Prein, A.F., Rasmussen, R.M., Ikeda, K., Liu, C.H., Clark, M.P., Holland, G.J. (2016) The future intensification of hourly precipitation extremes. NAT CLIM CHANGE, 7(1): 48-52. https://doi. org/10.1038/NCLIMATE3168

21. Qian, W., Fu, J. and Yan, Z. (2007) Decrease of light rain events in summer associated with a warming environment in China during 1961-2005. GEOPHYS RES LETT, 34(11): 224-238. https://doi. org/10.1029/2007GL029631

22. Rao, X.Q., Lu, X. and Dong, W.J. (2019) Evaluation and Projection of Extreme Precipitation over Northern China in CMIP5 Models. ATMOSPHERE-BASEL, 10(11): 1-19. https://doi.org/ 10.3390/atmos10110691

23. Ren, L., Xue, L.Q., Liu Y.H., Shi, J., Han, Q., Yi, P.F., (2017) Study on Variations in Climatic Variables and Their Influence on Runoff in the Manas River Basin, China. WATER-SUI, 9(4): 1-19. https://doi.org/10.3390/w9040258

24. Srivastava, A., Grotjahn, R. and Ullrich, P.A. (2020) Evaluation of historical CMIP6 model simulations of extreme precipitation over contiguous US regions. WEATHER CLIM EXTREME, 29: 100268. https://doi.org/10.1016/j.wace.2020.100268

25. Stouffer, R.J., Eyring, V., Meehl, G.A., Bony, S., Senior, C., Stevens, B., Taylor, K.E. (2017) CMIP5 SCIENTIFIC GAPS AND RECOMMENDATIONS FOR CMIP6. B AM METEOROL SOC, 98(1): 95-105. https://doi.org/10.1175/BAMS-D-15-00013.1

26. Swain, S. and Hayhoe, K. (2015) CMIP5 projected changes in spring and summer drought and wet conditions over North America. CLIM DYNAM, 44(9-10): 2737-2750. https://doi.org/10.1007/ s00382-014-2255-9

27. Thibeault, J.M. and Seth, A. (2014) Changing climate extremes in the Northeast United States: observations and projections from CMIP5. CLIMATIC CHANGE, 127(2): 273-287. https://doi. org/10.1007/s10584-014-1257-2

28. Wang, H.J., Wang, H.J., Sun, J.Q., Chen, H.P., Zhu, Y.L., Zhang, Y., Jiang, D.B., Lang, X.M., Fan, K., Yu, E.T., Yang, S. (2012) Extreme Climate in China: Facts, Simulation and Projection. METEOROL Z, 21(3): 279-304. https://doi.org/10.1127/0941-2948/2012/0330

29. Wang, W.G., Ding, Y.M., Shao, Q.X., Xu, J.Z., Jiao, X.Y., Luo, Y.F., Yu, Z.B. (2017) Bayesian multi-model projection of irrigation requirement and water use efficiency in three typical rice plantation region of 
China based on CMIP5. AGR FOREST METEOROL, 232: 89-105.

https://doi.org/10.1016/j.agrformet.2016.08.008

30. Wang, Y. and Li, Z. (2005) Observed trends in extreme precipitation events in China during 1961-2001 and the associated changes in large-scale circulation. GEOPHYS RES LETT, 32(17): 1-4. https://doi.org/10.1029/2005GL022574

31. Wu, J. and Gao, X.J. (2013) A gridded daily observation dataset over China region and comparison with the other datasets. Chinese J. Geophys, 56(4): 1102-1111. https://doi.org/10.6038/cjg20130406

32. Xu, H.W., Chen, H.P. and Wang, H.J. (2021) Future changes in precipitation extremes across China based on CMIP6 models. INT J CLIMATOL, 1-17. https://doi.org/10.1002/joc.7264

33. Xu, K., Xu, K., Xu, B.B., Ju, J.L., Wu, C.H., Dai, H., Hu, B.X. (2019) Projection and uncertainty of precipitation extremes in the CMIP5 multimodel ensembles over nine major basins in China. ATMOS RES, 226: 122-137. https://doi.org/10.1016/j.atmosres.2019.04.018

34. Xue, L., Xue, L.Q., Zhu, B.L., Yang, C.B., Wei, G.H., Meng, X.Y., Long, A.H., Yang, G. (2017) Study on the characteristics of future precipitation in response to external changes over arid and humid basins. SCI REP-UK, 7(1): 15148. https://doi.org/10.1038/s41598-017-15511-5

35. Zhang, W.X. and Zhou, T.J. (2020) Increasing impacts from extreme precipitation on population over China with global warming. SCI BULL, 65(3): 243-252. https://doi.org/10.1016/j.scib. 2019.12.002

36. Zhou, T., Zou, L. and Chen, X. (2019) Commentary on the Coupled Model Intercomparison Project Phase 6(CMIP6). CLIMATE CHANGE RESEARCH, 15(5): 445-456. https://doi.org/10. 12006/j.issn.1673-1719.2019.193

37. Zhu, B., Xue, L., Wei, G., Zhang, L. and Chen, X. (2018) CMIP5 projected changes in temperature and precipitation in arid and humid basins. THEOR APPL CLIMATOL, 136(3-4): 1133-1144. https://doi.org/10.1007/s00704-018-2542-1

38. Zhu, Y.L., Wang, H.J., Zhou, W. and Ma, J.H. (2011) Recent changes in the summer precipitation pattern in East China and the background circulation. CLIM DYNAM, 36(7-8): 1463-1473. https://doi.org/10.1007/s00382-010-0852-9

\section{Tables}

\section{Table 1}

Basic information about the $4 \mathrm{GCMs}$ in this study 


\begin{tabular}{|llllll|}
\hline Abbreviation & Model ID & $\begin{array}{l}\text { Country or } \\
\text { Union }\end{array}$ & $\begin{array}{l}\text { Atmospheric } \\
\text { resolution }\end{array}$ & $\begin{array}{l}\text { Integration } \\
\text { period }\end{array}$ & Type and size \\
\hline GE & $\begin{array}{l}\text { GFDL- } \\
\text { ESM4 }\end{array}$ & USA & $100 \mathrm{~km}$ & $1950-2100$ & $\begin{array}{l}\text { Daily } \\
\text { precipitation }\end{array}$ \\
\hline ME & MRI-ESM2 & Japan & $100 \mathrm{~km}$ & $1950-2100$ & $\begin{array}{l}\text { Daily } \\
\text { precipitation }\end{array}$ \\
\hline MI & MIROC6 & Japan & $250 \mathrm{~km}$ & $1960-2100$ & $\begin{array}{l}\text { Daily } \\
\text { precipitation }\end{array}$ \\
\hline IL & $\begin{array}{l}\text { IPSL- } \\
\text { CM6A-LR }\end{array}$ & France & $250 \mathrm{~km}$ & $1850-2100$ & $\begin{array}{l}\text { Daily } \\
\text { precipitation }\end{array}$ \\
\hline
\end{tabular}

Table 2

Characteristics of the extreme precipitation indices used

\begin{tabular}{|llll|}
\hline Number & Abbreviation & Definition & Unit \\
\hline 1 & PRCPTOT & $\begin{array}{l}\text { Daily accumulation of precipitation greater than or equal to } \\
1 \mathrm{~mm}\end{array}$ & $\mathrm{~mm}$ \\
\hline 3 & SDII & Precipitation intensity & $\mathrm{mm} / \mathrm{d}$ \\
\hline 4 & CDD & Consecutive dry days & days \\
\hline 5 & CWD & Consecutive wet days & days \\
\hline 6 & PG25 & Days in a year with precipitation greater than $25 \mathrm{~mm}$ & days \\
\hline 7 & Rx1day & Maximum 1-daily precipitation & days \\
\hline 8 & Rx5day & Maximum precipitation for 5 consecutive days & mm \\
\hline
\end{tabular}

\section{Figures}




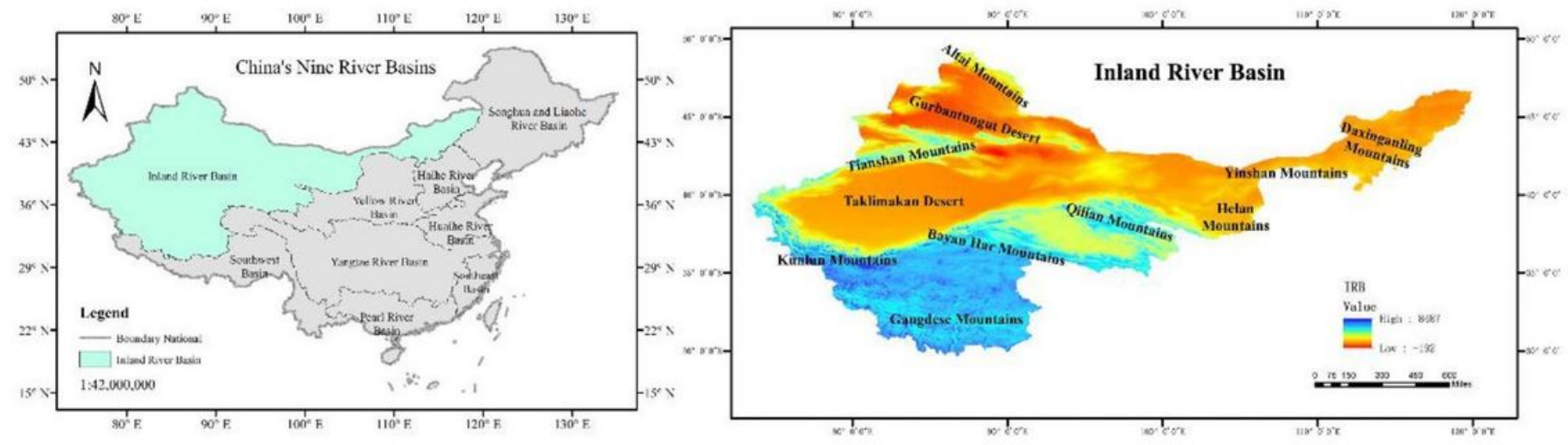

Figure 1

China's nine river basins and the geographical location of the study area
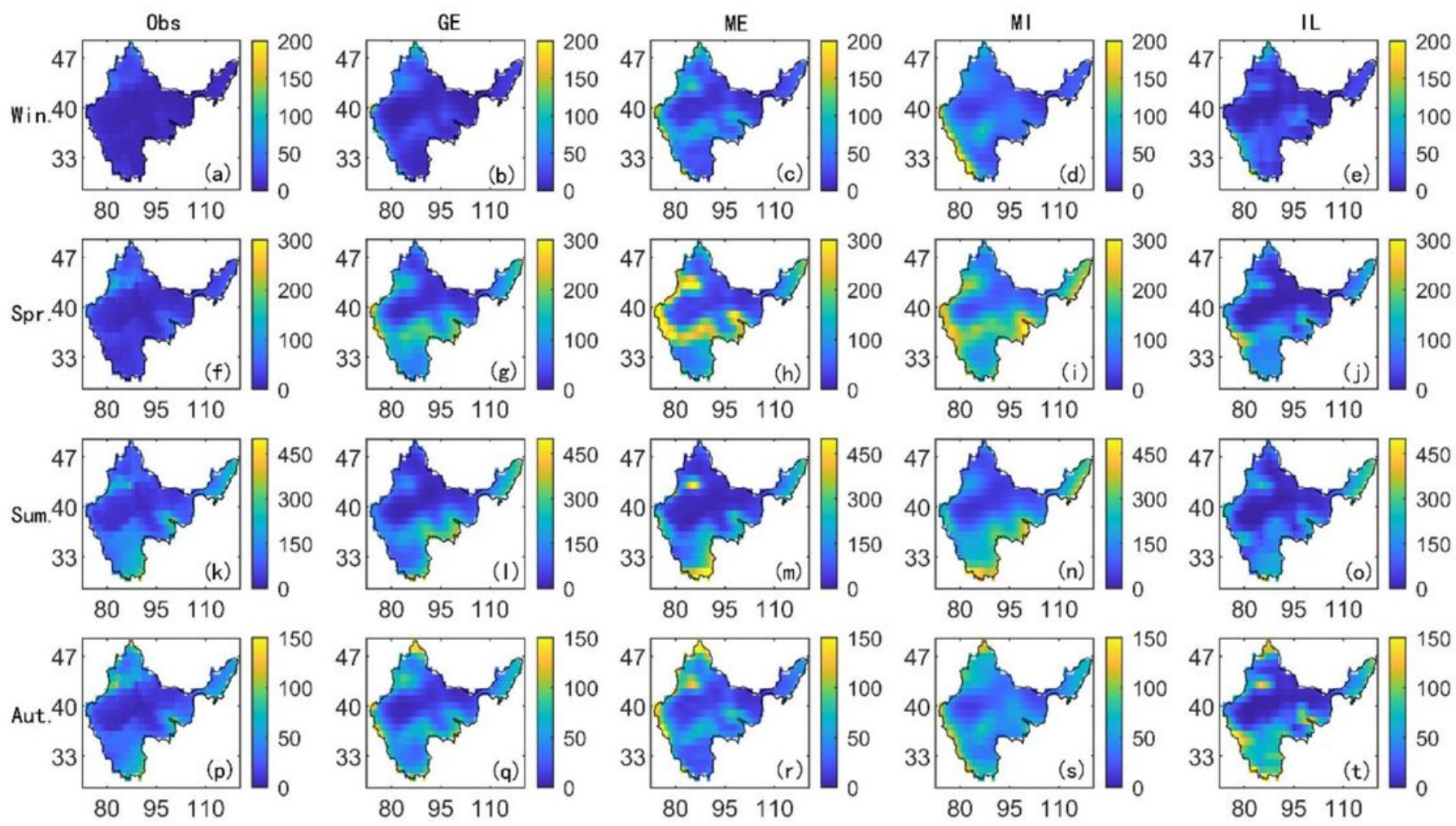

\section{Figure 2}

Seasonal changes of CN05.1 observation data and historical data of four CMIP6 climate models in the IRB 
Changes in the bias percentage and the RMSE of the CMIP6 model for precipitation observations from 1961 to 2014
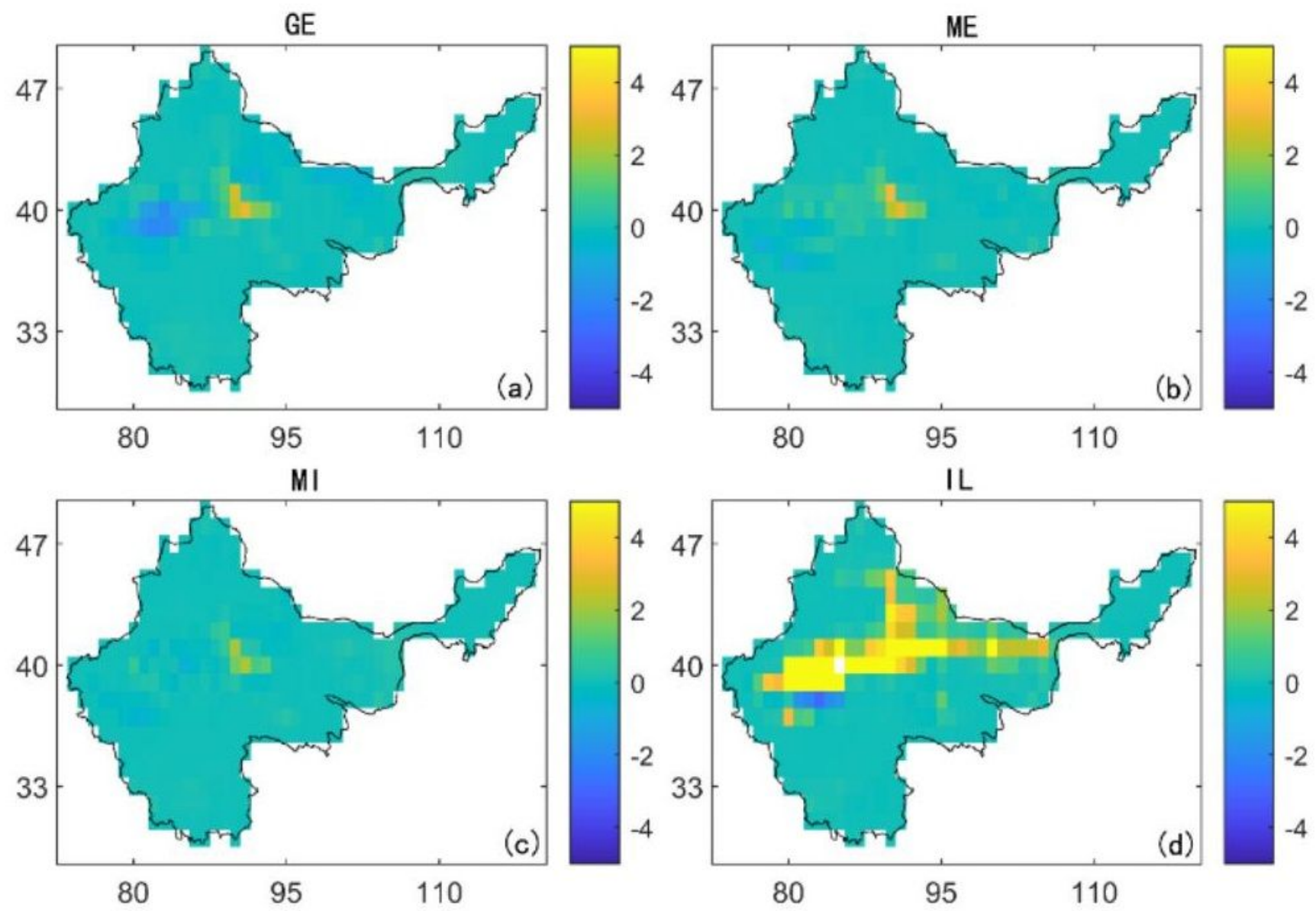

\section{Figure 4}

Bias percentage after correction for different CMIP6 GCM models from 1961 to 2014 

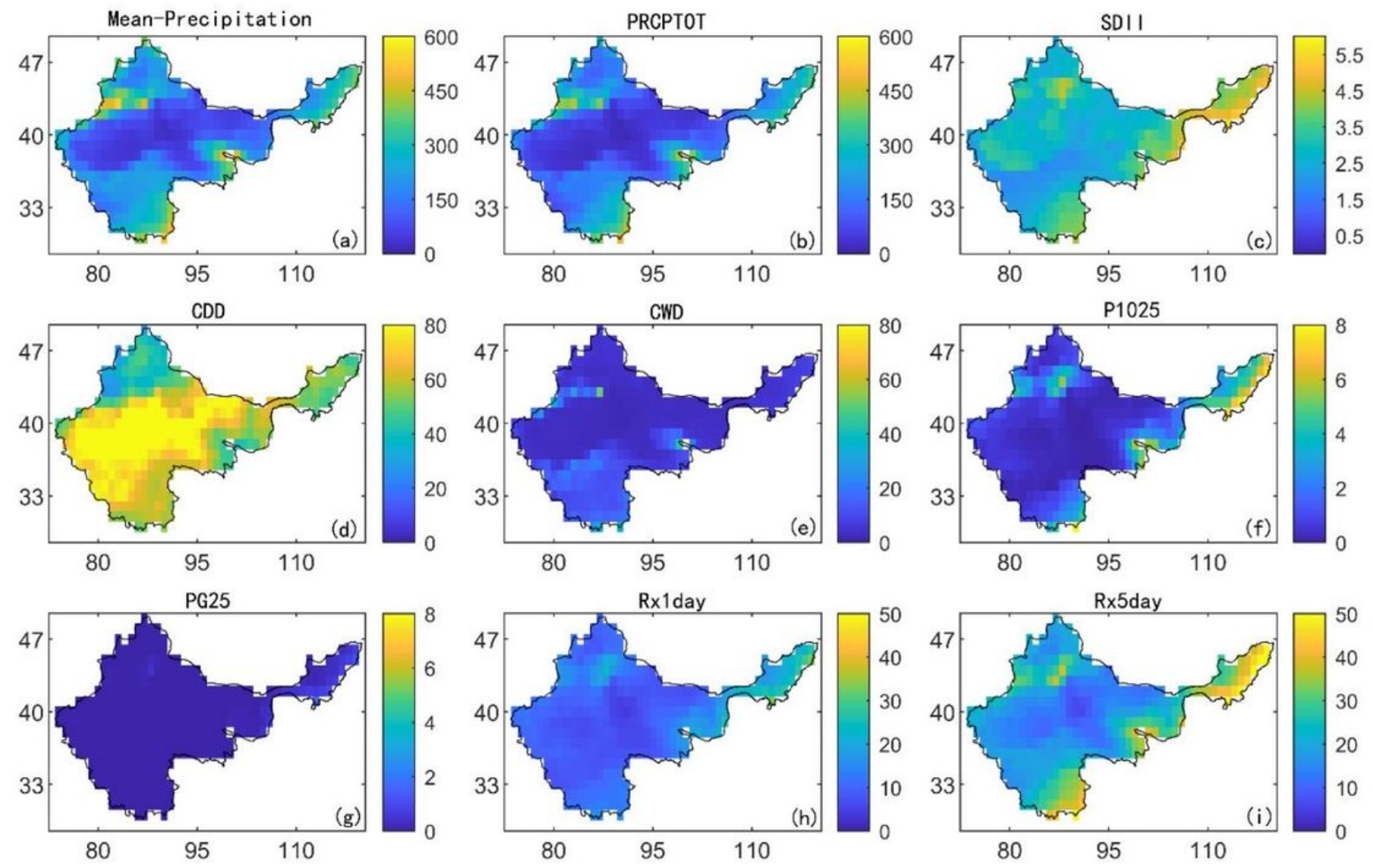

Figure 5

Changes in the extreme precipitation indices observed by grids in the IRB from 1961 to 2014 

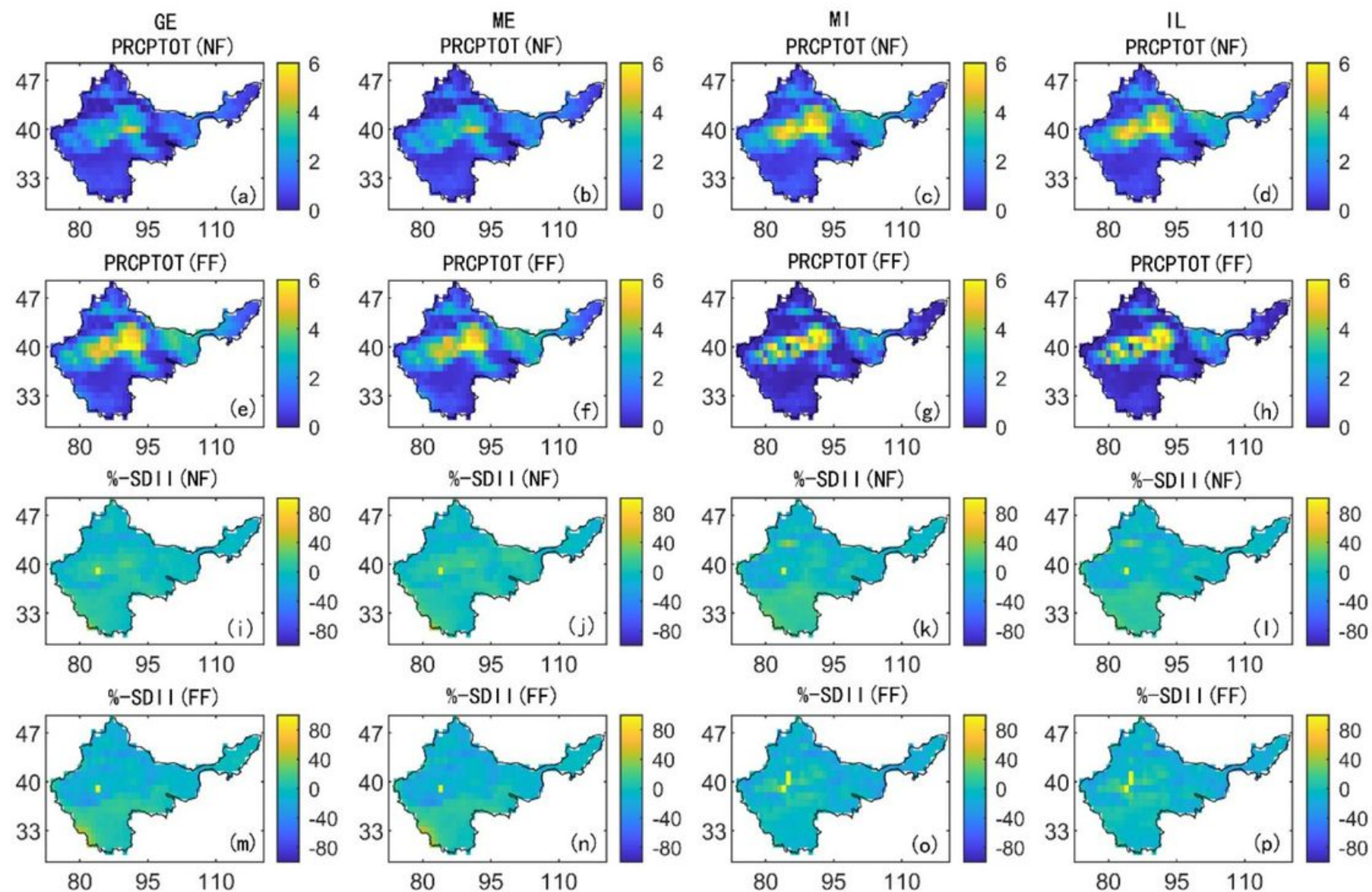

\section{Figure 6}

Calculate the PRCPTOT and the SDIl changes of all CMIP6 GCMs concerning the observed precipitation in the NF and the FF 

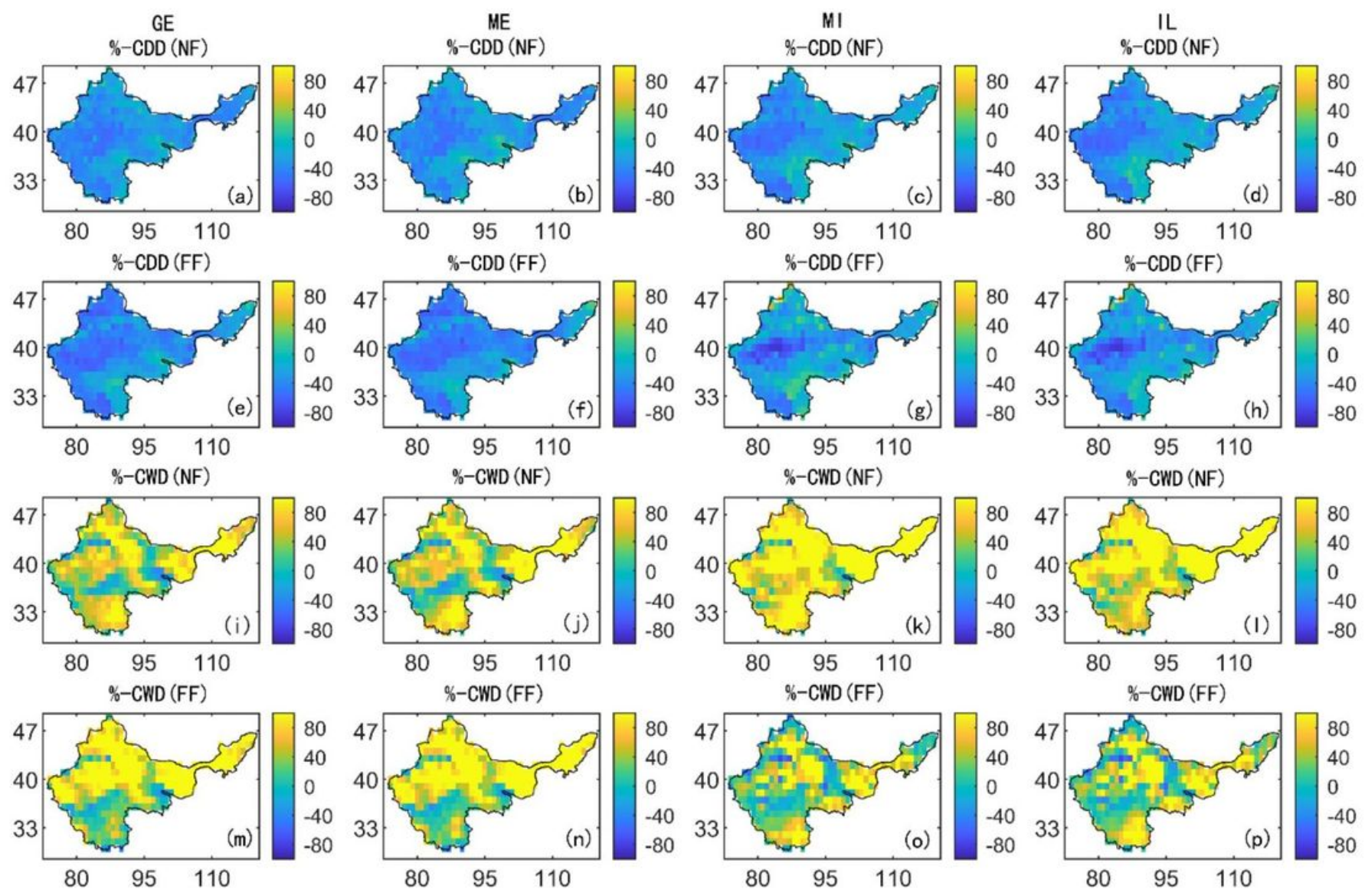

\section{Figure 7}

Calculate the percentage change of CDD and CWD of all CMIP6 GCMs concerning the observed precipitation in the NF and the FF

\section{Figure 8}

Calculate the percentage change of P1025 and P25 of all CMIP6 GCMs concerning the observed precipitation in the NF and the FF 

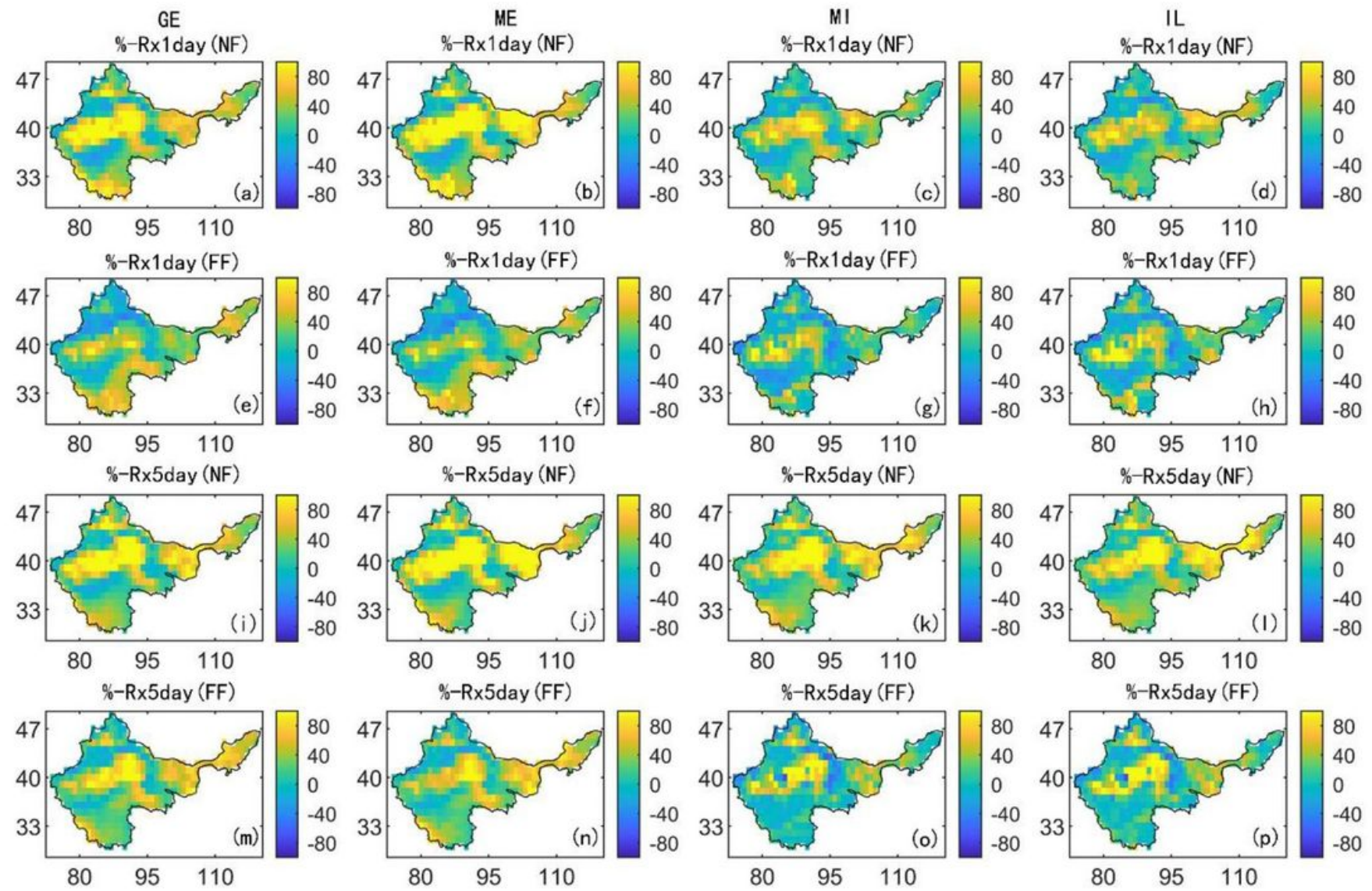

\section{Figure 9}

Calculate the percentage change of Rx1day and Rx5day of all CMIP6 GCMs concerning the observed precipitation in the NF and the FF 